\title{
Colipase and Maximally Activated Pancreatic Lipase in Normal Subjects and Patients with Steatorrhea
}

\author{
K. J. Gaskin, P. R. Durie, R. E. Hill, L. M. Lee, and G. G. Forstner, \\ Gastrointestinal Division and Kinsmen Cystic Fibrosis Research Center, \\ The Hospital for Sick Children, Toronto, M5G 1X8, Canada
}

A B S T R A C T Human pancreatic lipase in duodenal secretions was studied under conditions of maximal activation by porcine colipase and maximal inhibition by sodium taurodeoxycholate. In almost all samples, total lipase activity in $4 \mathrm{mM}$ sodium taurodeoxycholate was activated by the addition of porcine colipase. Activation was linear until saturation by cofactor was reached, and maximum activity was greater than that obtained in the absence of bile salts. At pH 8.0 in 4 $\mathrm{mM}$ sodium taurodeoxycholate, lipase activity was due to pancreatic lipase in samples from normal and steatorrheic individuals and was proportional to the concentration of endogenous colipase in samples that could be activated by exogenous colipase. In these samples, therefore, colipase activity could be conveniently assayed as the lipase activity at pH 8.0 in $4 \mathrm{mM}$ sodium taurodeoxycholate. Colipase to total pancreatic lipase ratios varied widely from individual to individual and on average were significantly lower in steatorrheic patients. In individual samples, colipase secretion was stimulated by pancreozymin and secretin roughly in parallel with total pancreatic lipase, but some variation in the ratio of the two was often seen in successive collection periods. Because pancreatic lipase is usually unsaturated with respect to cofactor, lipolytic activity in duodenal secretions may be finely controlled by modulation of colipase secretion.

\section{INTRODUCTION}

Pancreatic lipase in its pure form is inactive in the presence of the supramicellar bile salt concentrations characteristic of human duodenal secretions (1-3), but, in life, inactivation is prevented by cosecretion of the pancreatic protein cofactor colipase. Colipases have been isolated and purified from several species (4-7), including man (8), and appear to be quite similar, each

Received for publication 26 November 1980 and in revised form 5 October 1981. having a molecular weight of $\sim 10,000$, with $100 \pm 10$ amino acid residues, five disulfide bridges, and little or no carbohydrate (9). The ability to activate pancreatic lipase depends on binding sites for both lipase (10) and lipid micelles (11), and it is thought that the cofactor functions as a bridge between the enzyme and its triglyceride substrates $(12,13)$. In physiological solutions containing $8 \mathrm{mM}$ bile salt, lipase and colipase form a 1:1 complex (10). Maximum activation also occurs at a molar colipase:lipase ratio near unity (14). Colipases and pancreatic lipases are functionally interchangeable $(10,14,15)$ in a wide range of species, including the shark (10), although minor characteristics of the activation process, such as $\mathrm{pH}$ optimum, may vary $(10,15)$.

In duodenal secretions from 11 normal subjects after a test meal, Borgstrom and Hildebrand (16) found that lipase activity in $4 \mathrm{mM}$ sodium taurodeoxycholate was $66-89 \%$ of the activity reached by the addition of excess colipase. Hence, their data suggest that there was insufficient colipase in these samples to achieve complete activation of lipase. This observation is extremely important, because it implies that the rate of lipolysis could be regulated to a major extent by the cofactor. It is also evident that assays for pancreatic lipase in duodenal secretions, which were not carried out in the presence of excess colipase, might seriously underestimate the amount of enzyme secreted.

To study colipase:lipase interrelationships we determined lipase activity in $4 \mathrm{mM}$ sodium taurodeoxycholate, with and without the addition of exogenous porcine colipase in saturating amounts, in duodenal secretions from nine normal subjects after stimulation with pancreozymin and secretin. We have shown that lipase estimation in $4 \mathrm{mM}$ sodium taurodeoxycholate without added colipase is a simple assay for endogenous colipase when the latter is present in subsaturating quantities. Maximally stimulated lipase and colipase determinations have been extended to duodenal secretions from patients with pancreatic insufficiency 
and steatorrhea. We report that endogenous colipase is usually insufficient to saturate pancreatic lipase, and that the degree of saturation varies widely among individuals.

\section{METHODS}

Subjects. Duodenal juice was obtained from 15 patients with steatorrhea and 9 control subjects with normal fecal fat excretion. Four of the control subjects were paid volunteers, and their inclusion in the study was approved by the Human Experimentation Committee, The Hospital for Sick Children, Toronto.

Pancreatic stimulation tests. Pancreatic stimulation tests were performed on all subjects. The method was quantitative and an adaptation of a published method (17). After an overnight fast, a double-lumen tube was inserted into the duodenum under fluoroscope control with the proximal port opening into the second portion of the duodenum and a series of distal ports opening near the ligament of Treitz. A nonabsorbable marker solution $(0.5 \mathrm{ml}$ of $5 \%$ bromosulfophthalein in $20 \mathrm{ml}$ of $5 \%$ mannitol) was infused through the lumen of the proximal port at a constant rate of $1.6 \mathrm{ml} / \mathrm{min}$. The mixture of duodenal juice and marker was aspirated through the distal ports by intermittent low Gomco suction (Gomco Thermotic Drainage Pump, Gomco Surgical Manufacturers Corp., Buffalo, N.Y.) into flasks on ice. A separate nasogastric tube was inserted, and gastric juice was removed by intermittent low Gomco suction throughout the test period. Duodenal juice was collected for $20 \mathrm{~min}$ without stimulation, then for three consecutive 20 -min periods during which an intravenous infusion of pancreozymin and secretin (Boots Pure Drug Co., Nottingham, England) was maintained at a rate of $0.125 \mathrm{U} / \mathrm{kg}$ per min. Aspirates from each period were divided into $5-\mathrm{ml}$ aliquots and stored for $<7 \mathrm{~d}$ at $-20^{\circ} \mathrm{C}$ until analyzed.

Assays. For the estimation of fecal fat stools were collected for 3-5 $\mathrm{d}$ in a hospital ward after a minimum period of $48 \mathrm{~h}$ without pancreatic enzyme supplements. Dietary intake was allowed to vary with the appetite of the subject. Fat intake was determined by recording and weighing and reference to standard content tables. Fat output was estimated by the method of van der Kamer et al. (18) and was expressed as a percentage of fat intake.

Lipase activity was determined by titration with an automatic titration system (Methrohm Ltd., Herisau, Switzerland; Combi Titrator type 3D; components E300B, E425, E473, E402, and EA880). The assays were performed at $37^{\circ} \mathrm{C}$ in a glass mixing chamber with $5 \mathrm{ml}$ of buffer solution consisting of $150 \mathrm{mM} \mathrm{NaCl}, 1 \mathrm{mM} \mathrm{CaCl}$, and $2 \mathrm{mM}$ Tris$\mathrm{HCl}$ at $\mathrm{pH} 5.5-8.5$ as required. $250 \mu \mathrm{l}$ of glycerol tributyrate was used as the lipid substrate except when replaced by 250 $\mu$ l of pure olive oil (Bertoli, Novara, Italy). After the addition of the enzyme sample, the rate of hydrolysis was determined by titration with $0.0025 \mathrm{M} \mathrm{NaOH}$ to a constant $\mathrm{pH}$, once linear kinetics were established for a period of $5 \mathrm{~min}$. $1 \mathrm{U}$ of lipase activity is equivalent to $1 \mu \mathrm{mol}$ of $\mathrm{NaOH}$ consumed/ $\mathrm{min}$. Unless otherwise stated, all assays were performed at pH 8.0. To measure lipase activity in the presence of sodium taurodeoxycholate, $10 \mathrm{mM}$ sodium taurodeoxycholate was prepared in the usual buffer solution and diluted with buffer to obtain the required concentration. Bromosulfophthalein was assayed by the method of Seligson et al. (19).

Preparation of human colipase-deficient pancreatic lipase. Duodenal juice was concentrated eightfold by lyophilization and applied to a Bio-Gel P-6 (Bio-Rad Laboratories,
Richmond, Calif.) column $(2 \times 45 \mathrm{~cm})$. The eluate was collected in 5-ml fractions. Fractions 6-18, containing the lipase peak, were lyophilized to $2 \mathrm{ml}$ and applied to a Sephadex G-75 (Pharmacia Fine Chemicals, Uppsala, Sweden) column $(2 \times 85 \mathrm{~cm})$ which was eluted with $0.01 \mathrm{M}$ Tris-HCl buffer pH 8.0 containing $0.5 \mathrm{M} \mathrm{NaCl}$ and $1 \mathrm{mM}$ benzamidine (20). 1.2-ml aliquots were collected and assayed for lipase activity in the presence and absence of $4 \mathrm{mM}$ sodium taurodeoxycholate. Lipase activity in aliquots 56-65 was completely inhibited by $4 \mathrm{mM}$ sodium taurodeoxycholate and, therefore, judged to be free of colipase.

Preparation of porcine colipase. The powdered contents of 5 Cotazym capsules (Organon Canada Ltd., Toronto, Canada) were mixed in $10 \mathrm{ml}$ of distilled water and centrifuged at $5,000 \mathrm{~g}$ for $20 \mathrm{~min}$ in an L 2B centrifuge (DuPont Instruments-Sorvall, DuPont Co., Newtown, Conn.). The precipitate was discarded, and the supernatant was heated at $80^{\circ} \mathrm{C}$ for $15 \mathrm{~min}$, frozen, and concentrated by lyophilization to $20 \mathrm{ml}$.

\section{RESULTS}

Colipase activity can be defined in operational terms as the capacity to reactivate pure pancreatic lipase in the presence of supramicellar concentrations of bile salt $(16,21)$. The porcine colipase preparation used in these studies was therefore assessed by its ability to activate a human colipase-deficient pancreatic lipase in the presence of bile salts (Fig. 1). As shown in Fig. $1 \mathrm{~A}$, increasing concentrations of sodium taurodeoxycholate resulted in a progressive inhibition of this lipase preparation that was complete at $4 \mathrm{mM}$ sodium taurodeoxycholate. Porcine colipase added in $4 \mathrm{mM}$ sodium taurodeoxycholate (Fig. 1B) restored activity in a linear fashion until maximum activation was reached. Fig. IC shows results obtained by adding colipase in excess of this saturating dose to the pancreatic
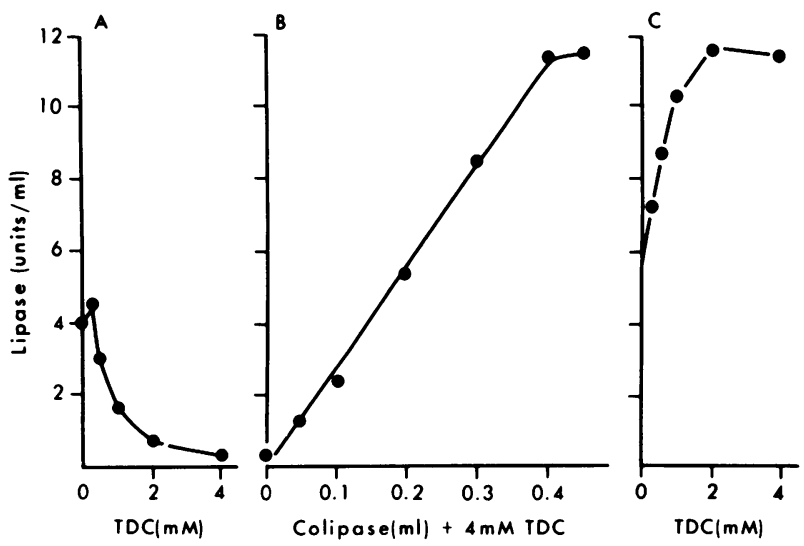

FIgUnie 1 Inhibition of colipase-deficient pancreatic lipase by sodium taurodeoxycholate (TDC) and activation by porcine colipase. (A) Lipase activity in the presence of increasing taurodeoxycholate concentrations. (B) Lipase activity in 4.0 $\mathrm{mM}$ taurodeoxycholate plus increasing volumes of colipase. (C) Lipase activity in excess colipase $(0.6 \mathrm{ml})$ with increasing concentrations of taurodeoxycholate. 
lipase as sodium taurodeoxycholate concentrations were increased. Maximum lipase activity was not obtained until sodium taurodeoxycholate concentrations reached the critical micellar concentration.

Fig. 2A illustrates the effect of adding increasing amounts of sodium taurodeoxycholate to a sample of duodenal juice obtained from a patient during stimulation with pancreozymin and secretin. At concentrations equal to or above the critical micelle concentration, lipase activity was progressively inhibited, as in the experiments depicted in Fig. 1. The lipase in the sample therefore resembled colipase-deficient pancreatic lipase in its sensitivity to taurodeoxycholate. Unlike the colipase-free pancreatic lipase preparation, however, residual activity in $4 \mathrm{mM}$ sodium taurodeoxycholate was appreciable, amounting to $48 \%$ of the starting lipase activity. The results shown in Fig. 2B confirm the impression that the duodenal juice was relatively deficient in colipase, because in $4 \mathrm{mM}$ sodium taurodeoxycholate the lipase activity of the sample was activated in a linear fashion by the addition of exogenous colipase in the same manner as the colipase-deficient pancreatic lipase (Fig. 1). Our initial results indicated that the lipase activity of the majority of the samples tested in $4 \mathrm{mM}$ sodium taurodeoxycholate was increased by the addition of exogenous colipase. In contrast to the experience of Borgstrom and Hildebrand (16), the maximum levels were always greater than those measured in the absence of added bile salts. The maximum activity obtained by adding colipase in the presence of $4 \mathrm{mM}$ sodium taurodeoxycholate will be referred to as total lipase to distinguish it from lipase estimations performed under other conditions. Total lipase provides the most accurate esti-
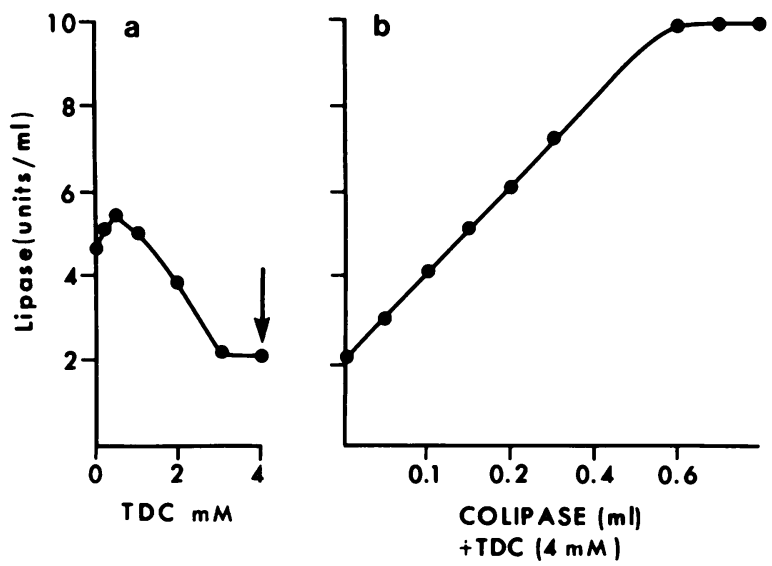

Figure 2 Inhibition of lipase in a duodenal aspirate (during pancreozymin-secretin stimulation) by (a) increasing concentrations of taurodeoxycholate (TDC) and (b) activation by the addition of exogenous porcine colipase. mate of pancreatic lipase, because activity is independent of fluctuation in endogenous colipase (16).

The origin of the residual lipase activity in $4 \mathrm{mM}$ sodium taurodeoxycholate (lipase measured without the addition of exogenous colipase) was established in several ways. It seemed likely that residual activity was due either to pancreatic lipase activated by endogenous colipase or to a second lipase with relative resistance to bile salt. Lipases of the latter type have been described in lingual and gastric secretions (22). Fig. 3 illustrates the $\mathrm{pH}$ activity profiles obtained with colipase-deficient pancreatic lipase (Fig. 3A) and stimulated duodenal juice from a patient with normal pancreatic function (Fig. 3B) in the presence of $4 \mathrm{mM}$ sodium taurodeoxycholate, with and without exogenous colipase. In the absence of exogenous colipase the colipase-free pancreatic lipase was inhibited completely by sodium taurodeoxycholate at every $\mathrm{pH}$, whereas in its presence, activity gradually increased to a maximum at $\mathrm{pH}$ 8.0. Thus, human pancreatic lipase is maximally activated by colipase at pH 8.0. Fig. 3B shows that the lipase activity in stimulated duodenal juice was also maximally activated by colipase at $\mathrm{pH} \mathrm{8.0,} \mathrm{even} \mathrm{though} \mathrm{there} \mathrm{is} \mathrm{a} \mathrm{shift} \mathrm{of} \mathrm{pH}$ optimum to $\mathrm{pH} 7.5$. Activation by exogenous colipase was not seen below $\mathrm{pH} 6.5$, suggesting that some of the lipase activity at lower $\mathrm{pH}$ might be due to enzymes other than pancreatic lipase. The marked inhibition by sodium taurodeoxycholate at $\mathrm{pH} 8.0$ indicates, however, that the dominant activity measured at this $\mathrm{pH}$ is that of pancreatic lipase.

In patients with very low pancreatic lipase secretion one might expect to see greater evidence of lipases of nonpancreatic origin in some samples. Fig. 4 shows the $\mathrm{pH}$ activity profile of a duodenal aspirate from a pa-

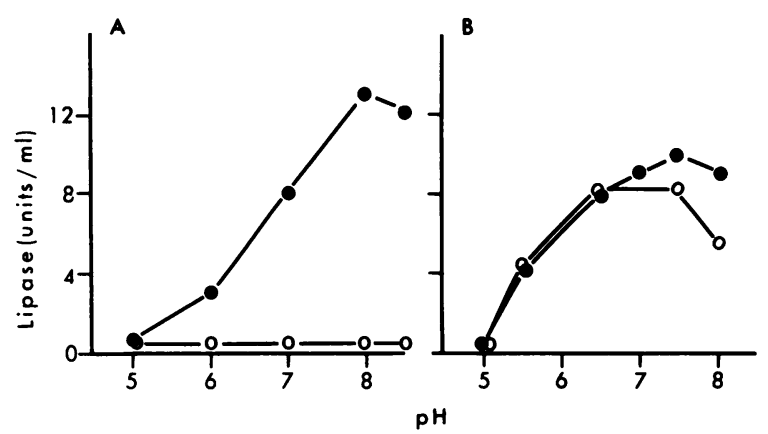

Figure 3 (A) Colipase-deficient pancreatic lipase activity in $4.0 \mathrm{mM}$ taurodeoxycholate at varying $\mathrm{pH}$ in the absence of exogenous colipase $(O)$ and in the presence of excess exogenous colipase (O). (B) Lipase activity in a duodenal aspirate (during pancreozymin-secretin stimulation) in $4.0 \mathrm{mM}$ taurodeoxycholate at varying $\mathrm{pH}$ in the absence of exogenous colipase $(O)$ and in the presence of excess exogenous colipase (○). 


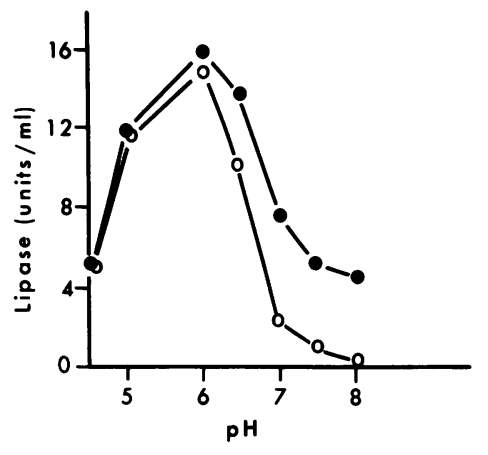

Figure 4 Lipase activity in an unstimulated duodenal aspirate from a patient with steatorrhea, in $4.0 \mathrm{mM}$ taurodeoxycholate at varying $\mathrm{pH}$. (O) No exogenous colipase; (๑) excess exogenous colipase. Conditions as described in Fig. 3.

tient with steatorrhea. The highest activity in the presence of both sodium taurodeoxycholate and sodium taurodeoxycholate plus colipase occurred at $\mathrm{pH} 6.0$, with little evidence of activation by colipase until $\mathrm{pH}$ 6.5. The $\mathrm{pH}$ profile strongly suggests that this sample contained a major bile salt-resistant lipase with a low $\mathrm{pH}$ optimum. The activity of this lipase in $4 \mathrm{mM}$ sodium taurodeoxycholate at $\mathrm{pH} 8.0$ must be extremely low, however, because almost $80 \%$ of the total activity at this $\mathrm{pH}$ resulted from activation by exogenous colipase. Thus, even in patients with very little pancreatic secretion, the measurement of lipase activity at $\mathrm{pH} 8.0$ appears to reflect predominantly pancreatic lipase.

Fig. 5 shows that lipase activity at pH 8.0 in $4 \mathrm{mM}$ sodium taurodeoxycholate is activated similarly by exogenous colipase in samples from different patients, even when containing different ratios of residual to total lipase. In this experiment, five samples were se-

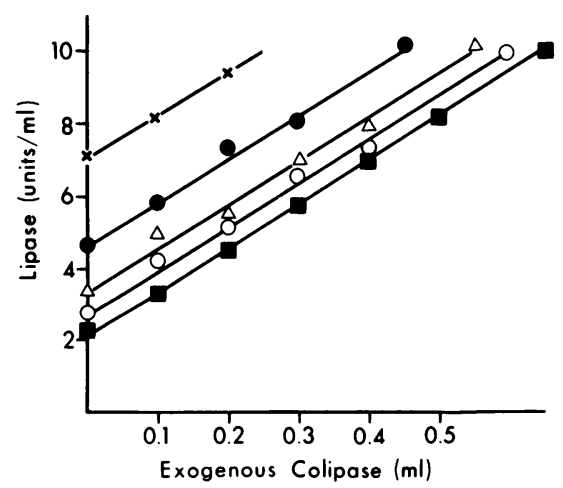

Figure 5 Lipase activity in stimulated duodenal aspirates from five patients selected for their range of inhibition by $4.0 \mathrm{mM}$ taurodeoxycholate. All samples were diluted to give a total activity per aliquot of $10 \mathrm{U}$ in the presence of excess exogenous colipase. Lipase was assayed in $4.0 \mathrm{mM}$ taurodeoxycholate in the presence of increasing concentrations of exogenous colipase. lected in which activity in sodium taurodeoxycholate varied from 20 to $70 \%$ of the total activity. All concentrations were adjusted so that the total lipase (activity in the presence of excess colipase) was identical. The samples, in a constant concentration of sodium taurodeoxycholate $(4 \mathrm{mM})$ were then activated by the addition of increasing amounts of exogenous colipase. As shown in Fig. 5, all samples exhibited parallel activation curves over a broad range of added colipase. The increments in lipase activity per unit of added colipase were therefore identical, regardless of the starting lipase activity. Because activation depends on the molar ratio of pancreatic lipase and colipase, equal activation per aliquot of exogenous colipase implies that all samples contained the same quantity of pancreatic lipase. Further, since the total activity after activation by excess colipase was constant in each case, this condition would only hold if the starting activity in sodium taurodeoxycholate were due solely to pancreatic lipase activated by endogenous colipase.

If so, lipase activity in $4 \mathrm{mM}$ sodium taurodeoxycholate ought to be directly proportional to the endogenous colipase in each sample. To test this hypothesis, we determined the colipase content of duodenal juice samples from seven different patients after heat inactivation of endogenous lipase in a manner similar to that described by Borgstrom and Hildebrand (16). Pancreatic lipase in duodenal juice was inactivated by heating at $80^{\circ} \mathrm{C}$ for $15 \mathrm{~min}$. The ability of these samples to activate a colipase-deficient pancreatic lipase sample was then tested at two to four serial dilutions. Identical aliquots were examined for residual lipolytic activity at $\mathrm{pH} 8.0$ in $4 \mathrm{mM}$ sodium taurodeoxycholate. It is evident in the results shown in Fig. 6 that there was a very high correlation between residual lipolytic activity in $4 \mathrm{mM}$ sodium taurodeoxycholate and activation of the colipase-deficient pancreatic lipase, over a broad range of activity, and further that there was negligible patient-to-patient variation. Measurement of lipolytic activity at $\mathrm{pH} 8.0$ in $4 \mathrm{mM}$ sodium taurodeoxycholate therefore reflects endogenous colipase content accurately and constitutes a convenient quantitative estimation of endogenous colipase, provided the latter is present in subsaturating amounts. Activation by colipase in heat-treated samples was constantly less than the activation produced by the endogenous colipase in $4 \mathrm{mM}$ sodium taurodeoxycholate, indicating that heat inactivation had destroyed some colipase as well as pancreatic lipase. Heat inactivation may therefore introduce a systematic error in the measurement of colipase. Inasmuch as heat inactivation was similar in all specimens, however, this error is irrelevant to the choice of methods, provided one remembers that results are not directly interchangable. 


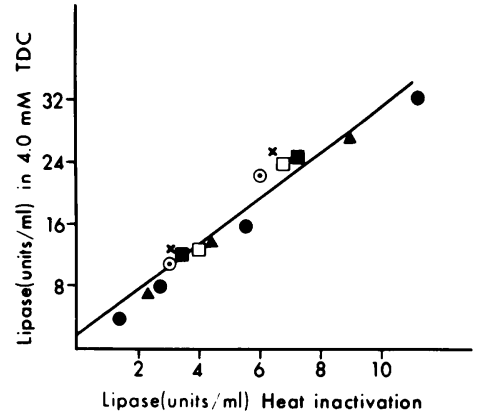

Figure 6 Comparison of lipase activity in $4.0 \mathrm{mM}$ taurodeoxycholate (TDC) without exogenous colipase and lipase activation of a colipase-deficient pancreatic lipase by an identical aliquot of the same sample of duodenal aspirate after its pancreatic lipase had been destroyed by heating at $80^{\circ} \mathrm{C}$ for $15 \mathrm{~min}$. Seven samples from seven patients were used at two or three dilutions (samples from individual patients have been given different symbols). The correlation between the two results $(y=1.68+2.99 x, r=0.96)$ was highly significant $(P<0.001)$.

The day-to-day and interassay variability of the assays for total lipase and colipase as estimated by the residual method in sodium taurodeoxycholate is shown in Table I. Both assays showed reasonably good reproducibility over a threefold activity range in intraday assays. The coefficient of variation for day-to-day testing was $6.6 \%$ for total lipase and $8 \%$ for colipase.

Both assays exhibited a linear increase in the rate of lipolysis with increasing enzyme concentration over at least a fivefold range of activity. Reaction rates required several minutes to achieve linearity when total lipase was measured, and occasionally required as long as $10 \mathrm{~min}$ when colipase was measured. Linear kinetics in both assays, once established, persisted for at least $20 \mathrm{~min}$.

Fig. 7A presents the mean responses to stimulation by pancreozymin and secretin of nine normal subjects during three 20 -min periods. Output of both colipase

TABLE I

Assay Variability for Total Lipase and for Colipase

\begin{tabular}{ccccc}
\hline & Total lipase & $\mathrm{CV}$ & Colipase & $\mathrm{CV}$ \\
\hline & $U / m l$ & $\%$ & $U / m l$ & $\%$ \\
Intraday $^{\bullet}$ & $10.55 \pm 0.73 \ddagger$ & 6.92 & $13.4 \pm 0.6$ & 4.5 \\
& $18.5 \pm 0.8$ & 4.5 & & \\
& $32.7 \pm 2.0$ & 6.1 & $46.9 \pm 2.1$ & 4.5 \\
Interday $^{\bullet}$ & $19.4 \pm 1.3$ & 6.6 & $14.2 \pm 1.1$ & 8.0 \\
\hline
\end{tabular}

$\mathrm{CV}$, coefficient of variation.

- Results based on 20 assays performed simultaneously or on consecutive days.

$\ddagger \pm$ SD. and total lipase was stimulated in both cases. Colipase output tended to increase in rough proportion to total lipase output for the group as a whole. The two individual responses shown in Fig. 7B make it clear, however, that the ratio of colipase to total lipase activity was not tightly fixed from period to period.

Cumulative 1-h poststimulation results are shown in Table II for 9 normal subjects and 15 patients with steatorrhea. Colipase and total lipase in the nine patients without pancreatic disease varied over a 3.3- to 4.7-fold range. The wide range was largely accounted for by one subject, however, who had almost twice the output of the second most responsive individual. Lipase activity in all of the subjects without pancreatic disease was stimulated by the addition of exogenous colipase. This is illustrated by the ratios of colipase activity to lipase activity, which varied considerably from subject to subject with a mean of 0.68 . Colipase and total lipase activities were extremely low in the patients with steatorrhea but, due to the sensitivity of the assay, could be measured in every case. The mean colipase secretion for the steatorrheic patients was $<0.1 \%$ of the mean colipase output, and total lipase was $<0.2 \%$ of the mean total lipase in the patients without pancreatic disease. The mean colipase:total lipase ratio of the steatorrheic patients was significantly lower than that of the patients with normal pancreatic function.

We have found very few samples that have not exhibited some activation with exogenous colipase and only one patient, a child with steatorrhea and very low lipase activity, failed to exhibit activation in a majority of the collection periods. The addition of a sample of duodenal juice to a colipase-deficient pancreatic lipase preparation resulted in this patient in activation of the pancreatic lipase. Colipase was therefore excreted in excess of pancreatic lipase.

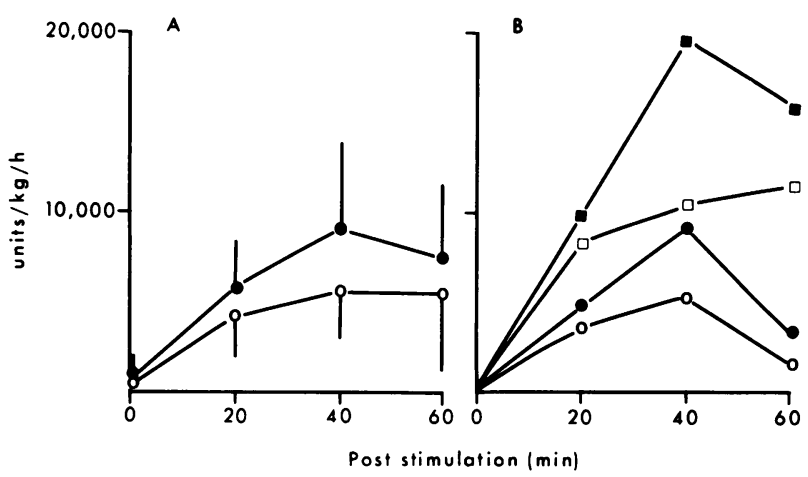

Figure 7 Basal and stimulated values for total lipase (O) and colipase (O). (A) Mean \pm SD in nine normal subjects. (B) Actual values in two representative subjects showing the variation in colipase and total lipase outputs from period to period. (๑), total lipase; (O), colipase. 
TABLE II

Total Lipase Activity and Colipase Activity in Normal Subjects and Patients with Steatorrhea due to Pancreatic Disease

\begin{tabular}{|c|c|c|c|c|c|c|}
\hline & \multicolumn{2}{|c|}{ Total lipase } & \multicolumn{2}{|c|}{ Colipase } & \multicolumn{2}{|c|}{ Colipase/total lipase } \\
\hline & Mean \pm SD & Range & $\operatorname{Mean} \pm S D$ & Range & Mean \pm SD & Range \\
\hline & \multicolumn{6}{|c|}{$U / \mathrm{kg} / \mathrm{h}$} \\
\hline Normal subjects & $22,766 \pm 11,023$ & $9,698-45,922$ & $15,122 \pm 7,887$ & $9,133-30,343$ & $0.68 \pm 0.14$ & $0.43-0.85$ \\
\hline Steatorrheic subjects & $48.3 \pm 67.7^{\circ}$ & $7-256$ & $15.5 \pm 18.0 \ddagger$ & $1.4-58.3$ & $0.47 \pm 0.24^{\mathrm{a}}$ & $0.10-0.94$ \\
\hline
\end{tabular}

All values in steatorrheic patients are significantly lower than those of normal subjects.

- $P<0.025$.

t $P<0.001$.

It was also of interest to determine whether activation with exogenous colipase occurred when a more physiological long-chain substrate was used as a substitute for glycerol tributyrate and, further, whether activation occurred at a more physiological $\mathrm{pH}$. We therefore assayed lipase activity with olive oil in the presence of $4.0 \mathrm{mM}$ sodium taurodeoxycholate with and without exogenous colipase in duodenal samples from three subjects without steatorrhea. Fig. 8 shows the results obtained over the $\mathrm{pH}$ range 6.5-8.5. Activity below pH 6.5 could not be measured satisfactorily, because the activity with the long-chain substrate was approximately 10 -fold lower than the activity with glycerol tributyrate. Activation by exogenous colipase was noted at $\mathrm{pH} 6.5$ and 7.0 and increased to a maximum at $\mathrm{pH} 7.5$ and 8.0. The concentration of endogenous colipase, therefore, appears to be less than optimal for lipolysis of long-chain triglyceride within the physiological $\mathrm{pH}$ range.

\section{DISCUSSION}

Even though colipase was first described in 1963 (23) and was soon shown to be essential for preserving ly-

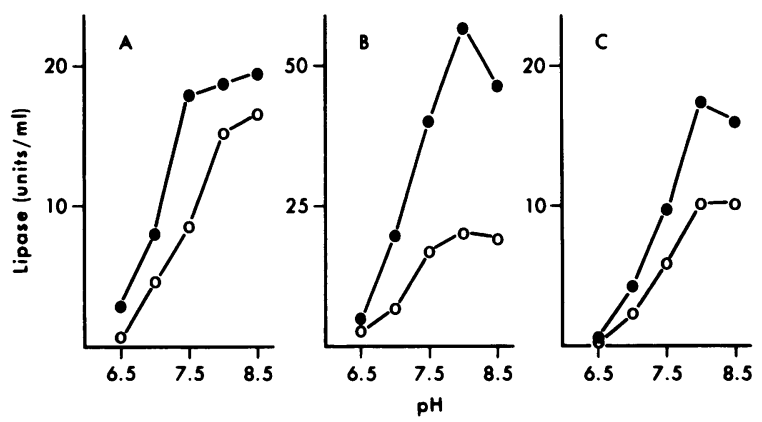

FIgure 8 Pancreatic lipase activity in $4.0 \mathrm{mM}$. Taurodeoxycholate at varying $\mathrm{pH}$ with $(\bullet)$ and without $(O)$ exogenous colipase, with olive oil as the lipid substrate. Samples from three patients (A, B, and C) were analyzed. polytic activity of pancreatic lipase in the presence of physiological concentrations of bile salts $(1,3)$, only one previous study has estimated lipase activity in pancreatic secretion in man with the addition of sufficient colipase to ensure optimum activation (16). Our work demonstrates that pancreatic lipase from almost all samples of basal and stimulated pancreatic secretions, both from individuals without apparent pancreatic disease and from patients with pancreatic insufficiency and steatorrhea, is inhibited by $4 \mathrm{mM}$ sodium taurodeoxycholate and stimulated by the addition of exogenous colipase, when assayed with the short-chain triglyceride substrate tributyrine. This observation may have an important physiological connotation, because it demonstrates that secreted pancreatic lipase is almost always unsaturated with respect to endogenous colipase. The rate of lipolysis was therefore dependent on the amount of endogenous cofactor in the secretions, as well as on the total pancreatic lipase, and, because lipase activity increased steeply and linearly with respect to added colipase in the unsaturated range, colipase has the potential for exerting very fine control over the rate of lipolysis. The probability that colipase might act in this manner is enhanced by the evidence presented in this paper that indicates that the ratio of colipase to maximally stimulated lipase varies considerably in samples from different individuals and to a minor degree in the same individual from secretion period to secretion period. There is, therefore, no evidence of a fixed ratio of colipase and pancreatic lipase that would suggest that the secretion of the cofactor is rigidly linked to that of the enzyme.

Borgstrom and Hildebrand (16) obtained results that suggested that colipase and pancreatic lipase were secreted in parallel in normal man. Pancreatic lipase was measured in the absence of bile salts and exogenous colipase, however, and not in the presence of excess colipase and supramicellar bile salt concentrations, as in our studies. Although Borgstrom and Hildebrand (16) found that there was no significant difference 
between determinations of lipase by the two methods, our results indicate that the assays can give quite different results in individual samples. The detailed study of exogenous colipase stimulation and bile salt inhibition presented in Fig. 3 provides a clear example of this sort, inasmuch as there is no correspondence between lipase levels under the two conditions. Our results indicate that both colipase and total lipase respond to stimulation by secretin-pancreozymin, and mean results in subjects without pancreatic disease indicate that the degree of stimulation is approximately the same over three 20 -min collections. Secretion of the enzyme and cofactor is, therefore, roughly parallel. In individual collection periods, however, there was often some variation in the cofactor:enzyme ratio during a single stimulation test, as if in response to a degree of independent control. Lipase activity in $4 \mathrm{mM}$ sodium taurodeoxycholate varied from 10 to $94 \%$ of the maximum activity produced by exogenous colipase, suggesting that endogenous colipase excretion could exert control over the rate of lipolysis over an eightfold to ninefold control range. Because patients with steatorrhea had the lowest ratios of colipase to total lipase it seems quite possible that the level of colipase in pathological secretions might at times be the deciding factor in determining whether fat malabsorption occurs.

The experimental basis for these observations lies in the evidence that lipase activity in $4 \mathrm{mM}$ sodium taurodeoxycholate at $\mathrm{pH} 8.0$ is entirely due to endogenous colipase and therefore is a measure of endogenous colipase. Using this assay, we have demonstrated an extremely close correlation among multiple patients with the standard approach to measuring colipase in pancreatic secretions, which depends upon heat inactivation of endogenous pancreatic lipase and the activation of a colipase-deficient enzyme preparation by the remaining heat-stable colipase. The heat inactivation assay is essential for detecting excess colipase in secretions that are saturated, but, as noted above, saturation appears to be uncommon in human pancreatic secretions. Our evidence also suggests that heat inactivation has important limitations, inasmuch as $\sim 60 \%$ of the endogenous colipase appeared to be destroyed by heat. Our conditions for heat inactivation were slightly more vigorous than those described by Borgstrom and Hildebrand (16), but we found them necessary to produce acceptable inactivation of lipase. Colipase may well be preserved, as suggested by Borgstrom and Hildebrand (16), by heating at lower temperatures for a shorter period, but inactivation of lipase is less complete, requiring rather large correction factors. There is, therefore, no absolutely satisfactory assay for colipase in the rare instances in which it is secreted in excess.
Borgstrom and Hildebrand (16) determined colipase activity after heat inactivation of duodenal samples by measuring reactivated pancreatic lipase activity at $\mathrm{pH}$ 7.0 rather than 8.0 because of their previous experience, predominantly with rat colipase, which indicated that maximum activation with colipase occurs at pH 6.0 (21). As we have illustrated in this paper, however, human pancreatic lipase is maximally activated by porcine colipase at a $\mathrm{pH}$ above 7.5-8.0 for both long- and short-chain triglyceride substrates. Similar results have been reported by Vandermeers et al. (15), using bovine colipase.

Both the assay for colipase and the assay for maximally activated (total) pancreatic lipase, using the short-chain triglyceride substrate, were extremely sensitive and could be extended to the measurement of activity in steatorrheic patients whose mean hourly outputs were $<0.1$ and $<0.2 \%$ of the mean results in patients without pancreatic disease for colipase and lipase, respectively. They, therefore, represent major advances over titrimetric assays using long-chain triglycerides, which suffer from poor linearity of product formation and insensitivity due to incomplete titration of fatty acids (24). All 15 steatorrheic patients had measurable amounts of colipase and lipase in every collection period and all showed some response to secretin-pancreozymin. In these patients, as shown in Fig. 4, lipase with a lower $\mathrm{pH}$ optimum and relative resistance to bile salts may contribute significantly to total lipolytic activity. Acid lipases in lingual glands and gastric contents are completely inactive at $\mathrm{pH} 8.0$ (22). It is, therefore, unlikely that an acid lipase of lingual origin would contribute to the residual lipase activity in sodium taurodeoxycholate at this $\mathrm{pH}$. That the steatorrheic patients as a group had significantly lower colipase:total lipase ratios when compared with those with normal pancreatic function is, therefore, doubly impressive.

\section{REFERENCES}

1. Morgan, R., J. Barrowman, and B. Borgstrom. 1969. The effect of sodium taurodeoxycholate and $\mathrm{pH}$ on the gel filtration behaviour of rat pancreatic protein and lipases. Biochim. Biophys. Acta. 175: 65-75.

2. Maylie, M. F., M. Charles, C. Gache, and P. Desnuelle. 1971. Isolation and partial identification of pancreatic colipase. Biochim. Biophys. Acta. 229: 286-289.

3. Morgan, R., and N. Hoffman. 1971. The interaction of lipase, lipase cofactor and bile salts in triglyceride hydrolysis. Biochim. Biophys. Acta. 248: 143-148.

4. Erlanson, C., P. Fernlund, and B. Borgstrom. 1973. Purification and characterization of two proteins with colipase activity from porcine pancreas. Biochim. Biophys. Acta. 310: 437-445.

5. Maylie, M. F., M. Charles, M. Astier, and P. Desnuelle. 1973. On porcine pancreatic colipase: large scale purification and some properties. Biochem. Biophys. Res. Commun. 52: 2191-2197. 
6. Rathelot, J., R. Julien, P. Canioni, and L. Sarda. 1975. Isolation and partial characterization of bovine pancreatic colipase. Biochimie (Paris). 57: 1123-1130.

7. Julien, R., J. Rathelot, P. Canioni, L. Sarda, J. Gregoire, and $H$. Rochat. 1978. Horse pancreatic colipase: isolation by detergent method and amino terminal sequence of the polypeptide chain. Biochimie (Paris). 60: 103-107.

8. Stennby, B., and B. Borgstrom. 1978. Purification and characterization of human pancreatic colipase. Biochim. Biophys. Acta. 572: 235-243.

9. Borgstrom, B., C. Erlanson-Albertsson, and T. Wieloch. 1979. Pancreatic colipase: chemistry and physiology. $J$. Lipid Res. 20: 805-816.

10. Patton, J. S., P. A. Albertsson, C. Erlanson, and B. Borgstrom. 1978. Binding of porcine pancreatic lipase and colipase in the absence of substrate by two-phase partition and affinity chromatography. J. Biol. Chem. 253: 4195-4202.

11. Charles, M., M. Astier, P. Sauve, and P. Desnuelle. 1975. Interactions of colipase with bile salt micelles. 1. Ultracentrifugation studies. Eur. J. Biochem. 58: 555-559.

12. Chapus, C., H. Sari, M. Semeriva, and P. Desnuelle 1975. Role of colipase in the interfacial adsorption of pancreatic lipase of hydrophilic interfaces. FEBS (Fed. Eur. Biochem. Soc.) Lett. 58: 155-158.

13. Semeriva, M., and P. Desnuelle. 1979. Pancreatic lipase and colipase. An example of heterogeneous biocatalysis. Adv. Enzymol. 48: 319-370.

14. Rathelot, J., R. Julien, P. Canioni, C. Coeroli, and L. Sarda. 1975. Studies on the effect of bile salt and colipase on enzymatic lipolysis. Improved method for the determination of pancreatic lipase and colipase. Biochimie (Paris). 57: 1117-1122.
15. Vandermeers, A., M. C. Vandermeers-piret, J. Rathe, and J. Christophe. 1974. On human pancreatic tricylglycerol lipase: isolation and some properties. Biochim. Biophys. Acta. 370: 257-268.

16. Borgstrom, B., and H. Hildebrand. 1975. Lipase and colipase activities of human small intestinal contents after a liquid test meal. Scand. J. Gastroenterol. 10: 585591.

17. Go, V. L. V., A. F. Hofmann, and W. H. J. Summerskill. 1970. Simultaneous measurements of total pancreatic, biliary and gastric outputs in man using a perfusion technique. Gastroenterology. 58: 321-328.

18. van der Kamer, H. H., H. Huinick, and H. A. Weyers. 1949. Rapid method for determination of fat in feces. J. Biol. Chem. 177: 347-351.

19. Seligson, D., J. Marino, and F. Dodson. 1957. Determination of sulfobromophthalain in serum. Clin. Chem. 3: 638-645.

20. Figarella, C., G. Negri, and H. Sarles. 1972. Presence of colipase in a congenital pancreatic lipase deficiency. Biochim. Biophys. Acta. 280: 205-210.

21. Borgstrom, B., and C. Erlanson. 1971. Pancreatic juice colipase. Physiological importance. Biochim. Biophys. Acta. 242: 509-513.

22. Hamosh, M., H. L. Klaevemen, R. O. Wolf, and R. O. Scow. 1975. Pharyngeal lipase and digestion of dietary triglyceride in man. J. Clin. Invest. 55: 908-913.

23. Baskys, B., E. Klein, and W. Lover. 1963. Lipases of blood and tissue. III. Purification and properties of pancreatic lipase. Arch. Biochem. Biophys. 102: 201-209.

24. Benzonana, G., and P. Desnuelle. 1968. Action of some effectors on the hydrolysis of long chain triglycerides by pancreatic lipase. Biochim. Biophys. Acta. 169: 47-58. 